\section{○}

OPEN ACCESS

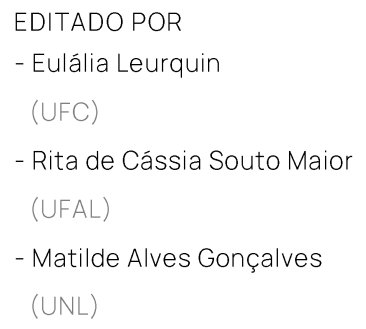

\title{
Sentidos e desafios da escrita acadêmica em um mestrado profissional
}

\author{
Raquel Aparecida Soares Reis FRANCO (1) \\ Instituto Federal de Educação, Ciência e Tecnologia de Minas Gerais (IFMG)
}

\section{RESUMO}

Neste texto, objetivamos compreender os sentidos e os desafios da escrita acadêmica dos discentes do Programa de Pós-Graduação em Educação Profissional e Tecnológica (ProfEPT). Buscamos, assim, identificar o que se escreve e para que se escreve no ProfEPT e quais desafios os alunos enfrentam ao escrever academicamente no ProfEPT. Exploramos uma abordagem social do letramento e dos Letramentos Acadêmicos (STREET, 1984, LEA; STREET, 1998, IVANIČ, 1998). Este estudo é de natureza qualitativa, adota uma perspectiva etnográfica (GREEN; BLOOME, 1997) e integra uma pesquisa mais ampla que ocorreu durante o ano de $2020 \mathrm{em}$ duas turmas do ProfEPT ofertadas pelo Instituto Federal de Educação, Ciência e Tecnologia de Minas Gerais (IFMG) no campus Ouro Branco. A análise das condições de produção da escrita, nesse contexto de formação, evidencia que as práticas de escrita não se limitaram tão somente aos gêneros produzidos no contexto acadêmico (dissertação, projeto de pesquisa, produto educacional, artigo, resenha, resumo e fichamento), mas está relacionada também a práticas específicas da academia com usos e significados próprios, como a formulação de questões e a redação. Dentre outros aspectos observados, destacamos que o principal desafio enfrentado pelos discentes ao escrever academicamente no mestrado profissional relaciona-se com os aspectos identitários e, logo, intertextuais.

\section{ABSTRACT}

In this text, we aim to understand the meanings and challenges of academic writing for students of the Graduate Program in Professional and Technological Education (ProfEPT). We aim to identify what is written 


\section{REVISTA DA ABRALIN}

and what is written for in ProfEPT. Moreover, what challenges do students face when writing academically at ProfEPT. We explore a social approach to literacy and Academic Literacy (STREET, 1984, LEA; STREET, 1998, IVANIČ, 1998). This study is qualitative in nature, adopts an ethnographic perspective (GREEN; BLOOME, 1997), and integrates a broader research that took place during 2020 in two classes of ProfEPT offered by the Federal Institute of Education, Science and Technology of Minas Gerais (IFMG) in the Ouro Branco campus. The analysis of the conditions of writing production, in this training context, showed that writing practices were not limited only to genres produced in the academic context (dissertation, research project, educational product, article, review, abstract and annotations), but it is also related to specific academic practices with their own uses and meanings, such as formulating questions and writing. Among other aspects observed, we highlight that the main challenge faced by students when writing academically in the professional masters is related to identity and, therefore, intertextual aspects.

\section{PALAVRAS-CHAVE}

Letramentos Acadêmicos. Mestrado Profissional. Práticas de Escrita Acadêmica. Identidade.

\section{KEYWORDS}

Academic Literacy. Professional Master's Degree. Academic Writing Practices. Identity.

\section{Introdução}

A produção escrita compõe um dos fatores que avaliam a qualificação dos pós-graduandos (PARIS, 2021). Em um mestrado, seja ele acadêmico ou profissional, são diversas as situações em que a escrita do discente é avaliada, por exemplo: na submissão de um artigo científico, no exame de qualificação, na escrita e defesa da dissertação, na elaboração e produção do produto educacional e outros.

No decorrer desse percurso acadêmico, como produtor de texto, o mestrando depara com a necessidade de construir uma identidade social compatível com a sua inserção no meio acadêmico (BEZERRA, 2015). E pelo fato de ele já ter realizado um curso de graduação, há uma expectativa institucional, por parte dos professores e coordenadores de cursos, por exemplo, que esses alunos já 


\section{REVISTA DA ABRALIN}

saibam lidar com as diversas práticas de letramento que ocorrem num programa de pós-graduação strictu sensu e sejam capazes de dominar a escrita acadêmica (BADENHORST; GUERIN, 2016)

Ao tratar sobre essa expectativa num curso de doutorado, Paris $(2021$, p.19) nos informa que ainda que os doutorandos "já tenham entrado em contato com algumas práticas de letramentos acadêmicos em seus anos de graduação e de mestrado, novas práticas e diferentes contextos surgem no doutorado, sem mencionar o fato de que tais discentes podem ser considerados pesquisadores em formação". Assim, para a pesquisadora, "os doutorandos, ao ingressarem e ao longo do curso, também possuem dificuldades legítimas".

Fiad (2013), na mesma direção de Paris (2021), ao discutir sobre essa problemática, nos lembra que há uma crença de que o letramento deva ser aprendido antes mesmo da entrada no ensino superior. Para ela, a visão de letramento como mero domínio de um conjunto de competências de leitura e de escrita embasa o mito de que o estudante deve chegar pronto à universidade. Esse mito se fortifica ainda mais no caso de alunos de pós-graduação.

Considerando o mito apresentado por Fiad (2013) e as expectativas institucionais com relação às práticas de escrita dos estudantes ingressantes de um mestrado, este texto objetiva compreender os sentidos e os desafios da escrita acadêmica dos discentes do Programa de Pós-graduação em Educação Profissional Tecnológica ${ }^{1}$ (ProfEPT), campus Ouro Branco, que atuam como professores em escolas públicas brasileiras. Buscamos, assim, identificar o que se escreve no ProfEPT, para que se escreve e quais desafios os alunos enfrentam ao escrever academicamente no mestrado profissional em questão.

Recorremos a uma abordagem social do letramento e dos Letramentos Acadêmicos (STREET, 1984, LEA; STREET, 1998, IVANIČ, 1998, LILLIS; SCOTT, 2007) para análise dos dados. Entendemos que o modelo dos Letramentos Acadêmicos considera as relações de poder e os conflitos ideológicos entre pessoas, instituições e identidades sociais. Compreendemos, dessa forma, que esse modelo é relevante para a análise das práticas letradas dos mestrandos na medida em que contempla, em seu quadro teórico epistemológico, a perspectiva dos participantes envolvidos e os significados que emergem dessas práticas, colocando "em primeiro plano a natureza institucional daquilo que conta comoconhecimento em qualquer contexto acadêmico especifico" (LEA; STREET, 2014, p. 479).

Este estudo é de natureza qualitativa e adota uma perspectiva etnográfica (GREEN; BLOOME, 1997). Assumimos, dessa forma, um viés interpretativo crítico que se centra nos fenômenos simbólicos e culturais das dinâmicas de ação no contexto organizacional da escola (SARMENTO, 2011). Os

\footnotetext{
${ }^{1}$ O ProfEPT é um programa de pós-graduação em Educação Profissional e Tecnológica, com um mestrado profissional em educação profissional e tecnológica em rede nacional, da área de ensino, reconhecido pela Coordenação de Aperfeiçoamento de Pessoal de Nível Superior (Capes), do Ministério da Educação (MEC). Conforme Brasil (2018), o programa tem como objetivo proporcionar formação em educação profissional e tecnológica aos profissionais da Rede Federal de Educação Profissional, Científica e Tecnológica (RFEPCT), visando tanto a produção de conhecimento como o desenvolvimento de produtos, por meio da realização de pesquisas que integrem os saberes inerentes ao mundo do trabalho e ao conhecimento sistematizado. O programa tem como pressupostos fundamentais a pesquisa como princípio pedagógico e o trabalho como princípio educativo. Dessa forma, considera como campos teóricos o "trabalho", a "educação" e o "ensino", reforçando a necessidade de uma educação politécnica e universal.
} 


\section{REVISTA DA ABRALIN}

dados apresentados neste texto fazem parte de uma pesquisa mais ampla de pós-doutoramento que foi desenvolvida durante o ano de 2020.

O artigo está estruturado em quatro seções. Na primeira delas, discutimos os modelos autônomo e ideológico de letramento que se apresentam a seguir. Na segunda seção, apresentamos o percurso teórico-metodológico da pesquisa. Continuando, analisamos os sentidos e os desafios da escrita acadêmica no ProfEPT. Finalmente, concluímos o artigo examinando implicações de nossa análise para as discussões sobre as práticas de escrita num mestrado profissional.

\section{Novos Estudos do Letramento}

Baseamo-nos teoricamente nos Novos Estudos do Letramento (NEL). Esse grupo rechaça a perspectiva que trabalha "com a suposição de que o letramento por si só - autonomamente - terá efeitos sobre outras práticas sociais e cognitivas" (STREET, 2013). De acordo com Street (2003), as interações a que a língua escrita se presta não são uniformes e, como mostram os estudos sobre letramento, são situadas, pois as interações são protagonizadas por sujeitos sociais e são historicamente constituídas, o que delineia geografias e temporalidades nos usos sociais da escrita.

Partindo desse princípio, os NEL rejeitam o modelo autônomo do letramento. Essa abordagem, conforme Street (2013), concebe que introduzir o letramento para as crianças na escola, para pessoas “iletradas" em vilarejos e para jovens pobres em áreas urbanas, entre outros, teria o efeito de intensificar suas habilidades cognitivas, melhorar suas perspectivas econômicas, torná-los cidadãos melhores, independentemente das condições sociais e econômicas que respondem pelo seu "iletrismo", em primeiro lugar (STREET, 2013, p.53).

A concepção descrita acima por Street (2013), simplesmente, impõe concepções particulares e dominantes de letramento a outras classes sociais, grupos e culturas. Essa perspectiva foi nomeada por Street $(1984 ; 2003)$ como modelo autônomo de letramento, pois disfarça as conjecturas culturais e ideológicas e as apresenta como se elas fossem neutras e universais. O modelo autônomo de letramento refere-se, basicamente, às habilidades individuais do sujeito. Nele estão incluídas as atividades de processamento da leitura, tanto as que ocorrem de forma consciente como as inconscientes, na construção do sentido do texto, ou seja, compreende o letramento como uma habilidade técnica e neutra.

Em oposição ao modelo autônomo, Street $(1984 ; 2013)$ sugere outro modelo, qual seja: o modelo ideológico de letramento. Segundo o autor, esse modelo oferece

[...] uma visão culturalmente mais sensível das práticas de letramento, pois elas variam de um contexto para outro. Esse modelo parte de premissas diferentes daquelas do modelo autônomo - ele postula, ao contrário, que o letramento é uma prática social, e não simplesmente uma habilidade técnica e neutra; que está sempre incrustado em princípios epistemológicos socialmente construídos. O modelo diz respeito ao conhecimento: as formas como as pessoas se relacionam com a leitura e a escrita estão, elas mesmas, enraizadas em concepções de conhecimento, identidade, ser. Está sempre incorporado em práticas sociais, tais como as de um mercado de trabalho ou de um contexto educacional específico, 


\section{REVISTA DA ABRALIN}

e os efeitos da aprendizagem daquele letramento em particular dependerão daqueles contextos específicos (STREET, 2013, p.53).

Ao caracterizar o modelo ideológico de letramento, Street (1993) salienta que não toma a noção de ideologia no velho sentido marxista ou antimarxista de falsa consciência ou dogma, mas vê a ideologia como o lugar da tensão entre a autoridade e o poder, de um lado, e a resistência e a criatividade, de outro, seguindo Bourdieu (1976) e Fairclough (1989), entre outros. Para Street (1993), essa tensão se dá no uso da língua na medida em que o modelo ideológico de letramento trata de uma concepção sustentada por princípios epistemológicos socialmente construídos em que as habilidades de leitura e de escrita são consideradas a partir das práticas sociais, relativas à inserção social das pessoas, seja em suas experiências pessoais, seja no cotidiano da sala de aula.

O modelo ideológico de letramento concentra-se, portanto, nas práticas específicas de leitura e de escrita. Esse modelo enfatiza a importância do processo de socialização na construção do significado do letramento para os participantes e, por isso, considera as instituições sociais, além da escola, como espaços em que esse processo também tem lugar. Dentro desse modelo, Lea e Street (1998) propõem que a escrita acadêmica seja tratada a partir da perspectiva dos letramentos acadêmicos que analisa os impactos a partir das relações de poder e de identidade (STREET, 1984).

É nessa perspectiva que Ivanič (1998) discute a relação entre escrita acadêmica e identidade. Conforme a autora, a escrita é um "ato de identidade" pelo qual as pessoas se alinham às possibilidades socioculturalmente delineadas de estar no mundo, reproduzindo ou contestando valores, crenças e interesses que são característicos de práticas e de discursos dominantes. Assim, para Ivanič (1998) refletir sobre identidade implica discutir sobre a noção de comunidade do discurso e de questões advindas dessa noção, tais como: intertextualidade, imitação e plágio na escrita acadêmica e questões de autoridade e postura autoral.

A noção de comunidade de discurso, para Ivanič (1998), é particularmente relevante para o estudo de identidade do escritor, pois cada indivíduo assume uma identidade em relação às comunidades com a qual entra em contato. A identidade da pessoa é construída por sua filiação, sua identificação, seus valores e suas práticas de uma ou mais comunidades. Segundo Ivanič (1998), uma das maneiras em que as pessoas se identificam com uma determinada comunidade é através do processo intertextual. Esse processo pode ocorrer de duas formas: a) a identidade de um escritor não é individual e nova, mas constituída pelos discursos que adota; b) a identidade de um escritor não é determinada completamente por outros discursos, mas, sim, pela maneira única como ele o desenha e o combina. Ao tratar sobre essas duas formas, Ivanič (1998) nos lembra que não é só uma questão de assumir as palavras dos outros, mas, também, assumir o papel dos outros. Em síntese, uma questão de autoridade e de postura autoral. Desse modo, quando escrevemos com o discurso de uma comunidade, assumimos a identidade de um membro desse grupo.

Considerando, então, a discussão teórica apresentada, no próximo tópico, iremos tratar sobre o percurso metodológico adotado neste estudo. 


\section{Percurso metodológico}

Durante o ano de 2020, realizamos uma pesquisa nas turmas de 2018 e 2019 do ProfEPT/IFMG com o objetivo de analisar as práticas de escrita desenvolvidas pelos mestrandos desse programa de pósgraduação. Para a realização da pesquisa, enviamos um questionário via google docs aos 35 alunos do curso, dos quais 26 responderam o questionário. A partir dessas respostas, foi possível traçar um perfil dos discentes.

O grupo pesquisado foi composto por 14 mulheres e 12 homens. Com relação à faixa etária, identificamos que 10 discentes possuem entre 28 e 37 anos de idade. Na faixa etária entre 38 anos e 47 anos há um total de 10 discentes. Há apenas um discente com menos de 27 anos e cinco discentes com idade acima de 48 anos de idade. Com relação à formação acadêmica, notamos uma grande diversificação, como destacamos no Gráfico 1 a seguir:

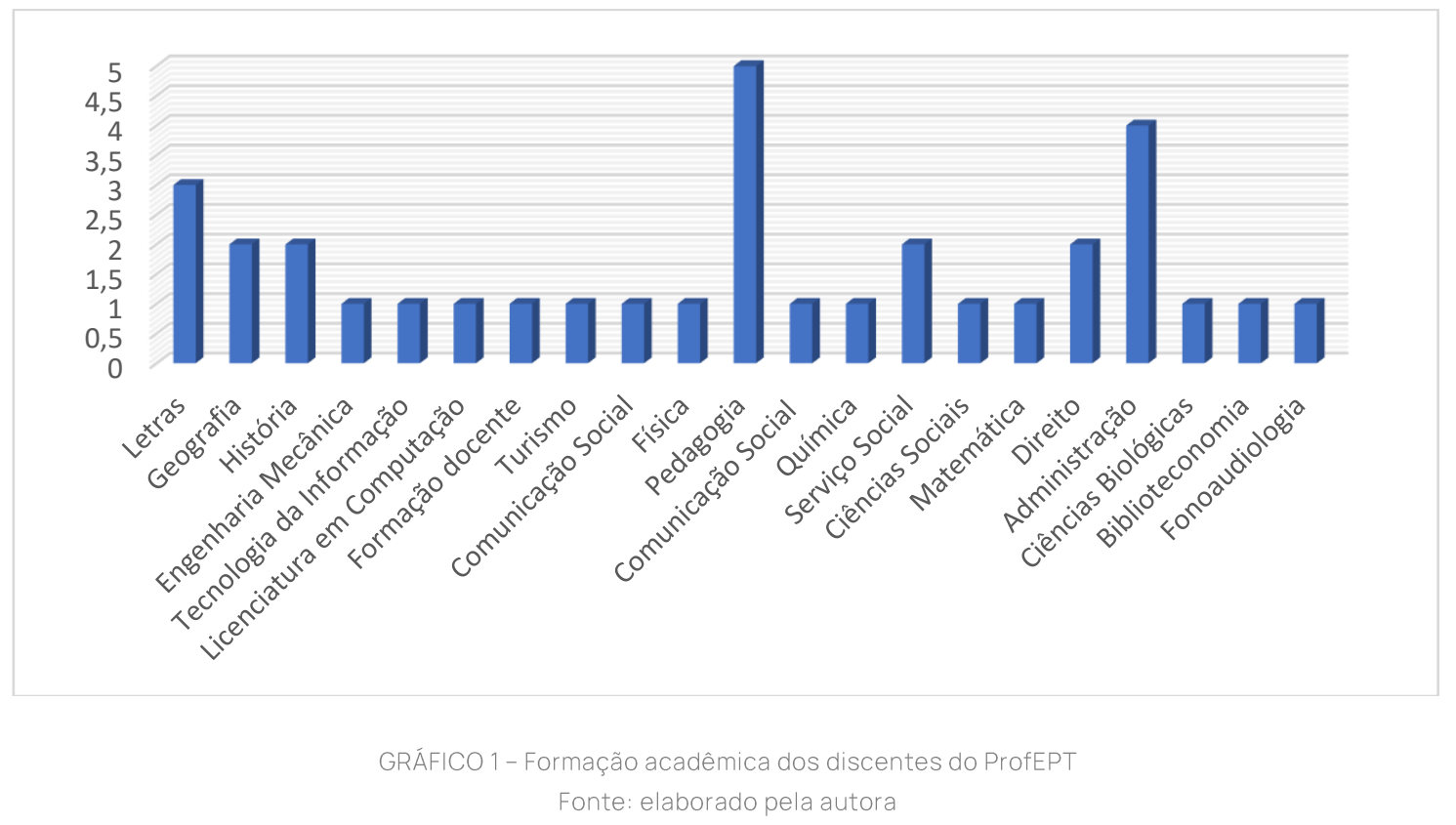

Pelo Gráfico 1, verificamos que a maior parte dos alunos que participaram da pesquisa possui curso de licenciatura ou formação pedagógica, totalizando $56 \%$. Os outros $44 \%$ dos discentes possuem bacharelado ou cursos tecnológicos. Dos 26 pesquisados, somente cinco são professores, sendo um professor de História, um de Inglês, um de Geografia, um de Física e um de Química. Esses professores atuam em instituições públicas municipais, estaduais e federais. Desses cinco docentes, escolhi três para participarem da entrevista. Selecionei como participantes mestrandos(as) de diferentes momentos do curso: dois participantes da $1^{\mathrm{a}}$ turma, iniciada em 2018, e um participante da $2^{\mathrm{a}}$ turma, iniciada em 2019. Os dois participantes selecionados da primeira turma do programa defenderam suas dissertações em 2020. O entrevistado da segunda turma estava na fase de qualificação e ainda não tinha iniciado sua pesquisa de campo. Essas entrevistas foram gravadas em áudio e foram 


\section{REVISTA DA ABRALIN}

descritas, analisadas e interpretadas segundo Wolcott (1994). O processo analítico envolveu, dessa forma, a exploração do princípio comparativo característico de estudos etnográficos (HEATH, 1982; STREET, 2001).

Na transcrição das entrevistas, os participantes foram identificados com nomes fictícios, escolhidos pela pesquisadora, de modo a garantir-lhes a confidencialidade das informações. As transcrições foram organizadas em unidades de mensagem que, segundo Castanheira e Green (2007, p. 33), "representam o menor nível de análise identificado na fala do falante". As convenções para transcrição de fala foram adaptadas de Kleiman e Matêncio (2005) e Neves (2010). As barras inclinadas representam unidades de mensagem; as palavras em maiúsculo indicam ênfase na fala da participante; as reticências indicam pausa e inconclusões; os colchetes, acréscimos ou cortes. Também acrescentamos o sublinhado para indicar uma ênfase apontada por nós.

A seguir, apresentamos uma breve descrição dos três participantes da pesquisa neste estudo:

\begin{tabular}{|c|c|c|c|}
\hline & PARTICIPANTE & FORMAÇÃO & ATUAÇÃO PROFISSIONAL \\
\hline \multirow[t]{2}{*}{$\begin{array}{l}\text { Participantes da } \\
\qquad \mathbf{1}^{\text {a }} \text { turma }\end{array}$} & Isaque, 35 anos. & $\begin{array}{l}\text { Licenciado em Física. } \\
\text { Especialização em Metodologia } \\
\text { do Ensino de Matemática e } \\
\text { Física. }\end{array}$ & $\begin{array}{l}\text { Professor da rede estadual de } \\
\text { ensino de Minas Gerais com } 5 \\
\text { anos de experiência. }\end{array}$ \\
\hline & Cleiton, 38 anos. & $\begin{array}{l}\text { Licenciado em História. } \\
\text { Especialização em Teoria e } \\
\text { Métodos de Pesquisa em } \\
\text { Educação. }\end{array}$ & $\begin{array}{l}\text { Professor da rede municipal de } \\
\text { Contagem e Ibirité com } 10 \text { anos } \\
\text { de experiência profissional. }\end{array}$ \\
\hline $\begin{array}{l}\text { Participantes da } \\
2^{\mathrm{a}} \text { turma }\end{array}$ & Wellington, 48 anos. & $\begin{array}{l}\text { Licenciado em Letras com } \\
\text { habilitação em Língua Inglesa. } \\
\text { Especialização em Ensino de } \\
\text { Língua Inglesa. }\end{array}$ & $\begin{array}{l}\text { Professor da rede federal de } \\
\text { ensino com } 20 \text { anos } \\
\text { experiência profissional. }\end{array}$ \\
\hline
\end{tabular}

\section{QUADRO 1 - Participantes da pesquisa \\ Fonte: elaborado pela autora}

É importante destacar que tomamos como critério para escolha dos entrevistados, os seguintes aspectos: o local de atuação profissional, a formação acadêmica e a temporalidade em termos de atuação profissional como docente. Selecionamos, assim, um professor que atua na rede federal, um que atua na rede estadual e outro que atua na rede municipal. Com relação ao tempo de atuação docente, optamos por professores em início de carreira e docentes com muitos anos de experiência. No que se refere à formação acadêmica, elegemos perfis diferenciados: um das ciências exatas, um da ciências humanas e um da linguagem.

Entendemos que esse perfil diferenciado nos fornece elementos para a compreensão dos sentidos e dos desafios da escrita dos discentes do ProfEPT que atuam como professores nas diversas esferas do ensino público brasileiro. Há uma expectativa de que o mestrado profissional possa contribuir para a promoção da melhoria da qualidade do ensino nos diferentes níveis de escolarização e, por extensão, do trabalho com a escrita nas escolas públicas brasileiras. 


\section{REVISTA DA ABRALIN}

\section{Sentidos e desafios da escrita acadêmica no ProfEPT}

Anteriormente, ao tratar dos modelos autônomo e ideológico de letramento, expus que o modelo ideológico reconhece a prática social implícita nos princípios socialmente construídos, pois os modos pelos quais as pessoas usam a escrita estão atrelados às concepções de conhecimento, à identidade e aos modos de ser e estar nas práticas sociais ou contextos particulares. Assim, neste artigo, buscamos compreender os sentidos e os desafios da escrita acadêmica dos discentes do ProfEPT, que são professores, a partir dos dados coletados no questionário e na entrevista e, em especial, nas primeiras questões realizadas aos participantes da pesquisa, quais sejam: Sabemos que, na universidade, produzimos/ escrevemos diversos gêneros textuais acadêmicos, quais são os principais gêneros produzidos por você no ProfEPT? Quais os principais desafios que você enfrentou na escrita desses textos? Você se recorda de um desses desafios que possa me narrar?

Partindo dessas perguntas, num primeiro momento, buscamos identificar o que se escreve e para que se escreve no ProfEPT. E, em seguida, almejamos compreender os desafios indicados pelos discentes ao escrever no curso.

Na universidade, nossas práticas de uso da língua, no caso desta pesquisa, a escrita, são relativamente estabilizadas pelo campo no qual os enunciados são produzidos e circulam: a própria esfera acadêmica. Assim, pelo relato dos discentes ocorridos por meio das entrevistas, foi possível perceber que os mestrandos produziram gêneros textuais que circulam no meio acadêmico. Para ter uma melhor visualização desses gêneros, elaboramos o Quadro 2, a seguir, que está organizado em quatro colunas. Na primeira coluna, identificamos o gênero nomeado pelo próprio participante da pesquisa; na segunda coluna, destacamos o nome do participante; na terceira, a unidade de mensagem; e, na última, apresentamos a função social do gênero apontada pelo próprio participante. 


\section{REVISTA DA ABRALIN}

\begin{tabular}{|c|c|c|c|}
\hline $\begin{array}{l}\text { GÊNERO } \\
\text { TEXTUAL }\end{array}$ & PARTICIPANTES & UNIDADE DE MENSAGEM & $\begin{array}{l}\text { FUNÇÃO DO GÊNERO } \\
\text { NA ESCRITA }\end{array}$ \\
\hline Fichamento & Isaque & $\begin{array}{l}\text { o fichamento/foi algo/ que ajudou/muito/ } \\
\text { na condução/ na triagem/ posição do } \\
\text { referencial teórico/ }\end{array}$ & $\begin{array}{l}\text { Triagem do referencial } \\
\text { teórico }\end{array}$ \\
\hline Resenha & Isaque & $\begin{array}{l}\text { as resenhas [...] foram base/ na escrita da } \\
\text { dissertação/ eu recorri/ algumas das } \\
\text { resenhas/que/ desenvolvi/ principalmente/ } \\
\text { na disciplina de Bases Conceituais / }\end{array}$ & $\begin{array}{l}\text { Base para a escrita de } \\
\text { outro gênero }\end{array}$ \\
\hline Resumo & Cleiton & $\begin{array}{l}\text { Tinha um certa forma de resumo/ mas acho/ } \\
\text { que/ nesse nivel/ a gente nunca/ usa/ o } \\
\text { termo/ resumo/ seria meio/ que/ uma } \\
\text { análise critica/assim/do texto/ }\end{array}$ & Análise crítica do texto \\
\hline $\begin{array}{l}\text { Formulação } \\
\text { de questão }\end{array}$ & Cleiton & 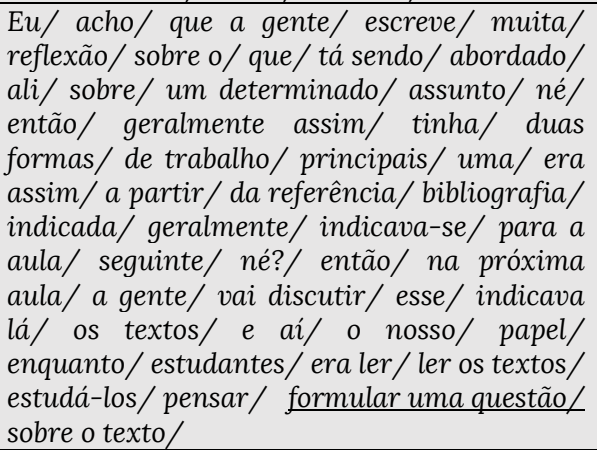 & $\begin{array}{l}\text { Reflexão sobre o que } \\
\text { está lendo }\end{array}$ \\
\hline Artigo & Isaque & $\begin{array}{l}\text { Houve algo/ que/ eu/ resgatei/ da } \\
\text { universidade/ que/ foi/ a publicação de } \\
\text { artigos/ né/ a gente/ escreveu/ conseguiu/ } \\
\text { duas/atividades acadêmicas/ }\end{array}$ & $\begin{array}{l}\text { Resgate da cultura } \\
\text { universitária } \\
\\
\text { Participação de } \\
\text { atividades acadêmicas }\end{array}$ \\
\hline Redação & Wellington & $\begin{array}{l}\text { Eu me lembro que/ no começo do programa/ } \\
\text { alguns professores/ já pediram que/ } \\
\text { escrevessem uma redação/ qual seria/ uma } \\
\text { de nossas inquietações / partindo de } \\
\text { experiências/ pessoais/daquilo/ que a gente } \\
\text { vive/e/no nosso/trabalho [...] }\end{array}$ & $\begin{array}{l}\text { Apresentar } r \text { as } \\
\text { inquietações a partir } \\
\text { das vivências pessoais e } \\
\text { profissionais. }\end{array}$ \\
\hline Memorial & Cleiton & $\begin{array}{l}\text { [...] eu acho/ que é/ outro exercício bacana/ } \\
\text { que nos faz refletir/ sobre o percurso/ e/ } \\
\text { coisas/ que/ talvez a gente/ nem tinha } \\
\text { pensando/mas/ só/ seguindo/o ritmo/e a } \\
\text { gente/ para pensar naquela/ escrita do } \\
\text { memorial. }\end{array}$ & $\begin{array}{lll}\text { Reflexão } & \text { sobre } & \text { o } \\
\text { percurso } & & \end{array}$ \\
\hline Projeto & Cleiton & $\begin{array}{l}\text { [...] e/ ai/ teve uma parte/ do projeto/ } \\
\text { também/. }\end{array}$ & $\begin{array}{l}\text { Não indicado pelo } \\
\text { participante }\end{array}$ \\
\hline Dissertação & Isaque & [...] e a dissertação/ propriamente dito/ & $\begin{array}{l}\text { Não indicado pelo } \\
\text { participante }\end{array}$ \\
\hline $\begin{array}{l}\text { Produto } \\
\text { educacional }\end{array}$ & Isaque & [...] o produto educacional/também/. & $\begin{array}{l}\text { Não indicado pelo } \\
\text { participante }\end{array}$ \\
\hline
\end{tabular}

QUADRO 2 - Gêneros textuais citados pelos participantes

Fonte: elaborado pela autora

Subdividimos o Quadro 2 em quatro categorias que foram marcadas com cores diferenciadas aleatoriamente, a saber: cinza, azul, laranja e verde. A cor cinza representa os gêneros que tiveram a função indicada pelos pesquisados como sendo os gêneros que permitem a triagem da bibliografia que se vai selecionar, tanto para a elaboração de algum trabalho científico, quanto para a atualização 


\section{REVISTA DA ABRALIN}

bibliográfica. É possível perceber que esses gêneros possibilitaram aos discentes refletir e realizar análise crítica do que estavam lendo. Dentre essas unidades de mensagem marcadas de cinza, destacamos a que foi dita por Cleiton: "Tinha uma/certa forma de resumo/ mas acho/ que nesse nível/ a gente/ nunca/ usa o termo resumo/ seria meio que/ uma análise crítica/ assim/do texto/".

Na fala do Cleiton, acima, observamos uma certa confusão ao denominar o gênero. Parece-nos que para ele, o resumo não é feito num nível de mestrado, somente na Educação Básica. Essa percepção do pesquisado vai ao encontro de uma pesquisa realizada no nível fundamental de ensino por Schneuwly e Dolz (1999, p.14). Nesse estudo, os pesquisadores revelam que a cultura do sistema escolar define o resumo como uma representação sintética do texto que será resumido, "sendo o problema de escrita reduzido a um simples ato de transcodificação da compreensão do texto". Assim, para Cleiton, num resumo não há possibilidade de realizar uma análise crítica do que vai ser resenhado, daí a proposição de outro gênero pelo participante: análise crítica.

A cor azul destaca o artigo científico. Para Isaque, a produção desse gênero acadêmico o possibilitou resgatar sua cultura universitária, pois ele participou de dois eventos acadêmicos: um no Centro Federal de Educação Tecnológica de Minas Gerais e outro na Universidade de Viçosa. Essa percepção da função social do gênero artigo apontada por Isaque corresponde ao afirmado por Bezerra (2015, p.69), quando indica que esse gênero, no contexto acadêmico, "emerge do e para o diálogo entre os pesquisadores". Segundo o referido autor, no mundo acadêmico, a produção de um artigo científico pode levar a uma apresentação oral em congressos e em seminários. Ademais, a produção de artigos científicos pode se configurar como uma etapa preparatória do mestrando para a sua inserção no mundo real da pesquisa científica, o que o torna autor e deixa de ser mero consumidor de gêneros acadêmicos. (BEZERRA, 2012).

Já a cor laranja refere-se aos gêneros, que segundo os pesquisados, tiveram a função de apresentar e de refletir sobre o percurso pessoal, profissional e acadêmico. As ditas "redação" e "memorial" foram solicitadas pelos professores na disciplina Seminário de Pesquisa. No ementário da referida disciplina, evidenciamos que essa discute atualidades das pesquisas em ensino e educação. Seminário de Pesquisa trata, também, das temáticas que envolvem as linhas de pesquisa do programa que tem como foco "o desenvolvimento de pesquisa aplicada aos processos de ensino, em espaços formais e não formais; ao desenvolvimento e à análise de materiais didáticos e ao uso de tecnologias para melhoria do processo de ensino e de aprendizagem" (BRASIL, 2018).

Analisando o ementário, percebemos a importância dos gêneros "redação" e "memorial" no contexto dessa disciplina visto que o aluno, ao participar do ProfEPT, realiza tão somente um teste com questões de múltipla escolha. Esses alunos não precisam apresentar um pré-projeto de pesquisa como ocorre na maioria das instituições de ensino que ofertam programa strictu sensu. Dessa forma, a intenção com esse memorial é que os alunos reflitam sobre o seu processo formativo e aliem essas reflexões à sua pesquisa futura.

Por último, a cor verde refere-se aos gêneros citados pelos pesquisados, mas que não foi indicada a função desses durante o curso. Talvez isso ocorra, dado que esses gêneros (projeto de pesquisa, dissertação e produto educacional) são os que norteiam todo o processo formativo do 


\section{REVISTA DA ABRALIN}

mestrando no ProfEPT. Em outras palavras, esses gêneros não estão relacionados a uma única disciplina e, sim, à etapas no processo formativo do mestrando O projeto de pesquisa orienta o início da trajetória acadêmica do estudante. Já o produto educacional e a dissertação são os gêneros que serão produzidos para que ocorra a defesa e, logo, o término do mestrado.

Com relação aos desafios enfrentados para escrever academicamente no ProfEPT, o discente Wellington nos narra que

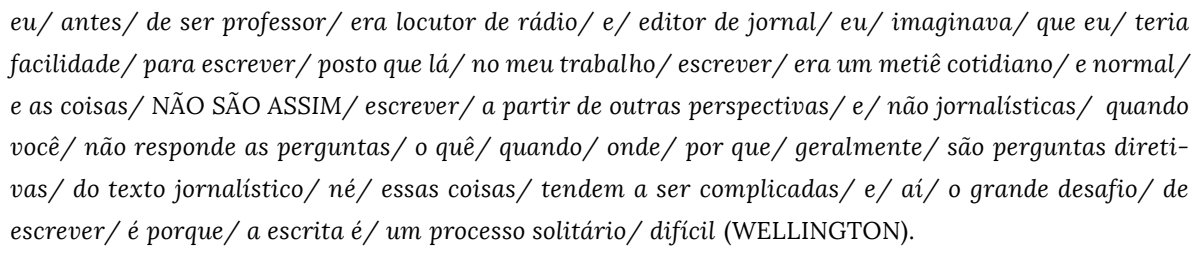

Na fala do pesquisado, observamos que, antes de ser professor, ele era locutor de rádio e, devido a isso, considerava que teria facilidade para escrever no ProfEPT. Porém, ao longo da sua trajetória no programa, observou que a escrita acadêmica difere do texto jornalístico. Talvez, para Wellington, a escrita acadêmica não é tão diretiva como a escrita jornalística. Essa sensação de Wellington vai ao encontro do afirmado por Lea (1999) quando a pesquisadora nos informa que aprender na universidade envolve novas formas de compreensão, de interpretação e de organização do conhecimento. Fiad (2011), ao tratar sobre esse assunto, nos diz, também, que há usos específicos da escrita no contexto acadêmico, usos esses que se diferem de outros contextos, inclusive de outros contextos de ensino.

Ao dizer: "e as coisas/ NÃO SÃO ASSIM/ escrever a partir de outras perspectivas", Wellington enfatiza e nos chama atenção para o fato de que a construção discursiva da identidade do estudante via escrita acadêmica implica não só aprender a usar a escrita, mas também a utilizar os discursos de outros de maneira própria. Trata-se, portanto, de uma caminhada empreendida pelo estudante em busca de uma "voz pessoal" na escrita acadêmica (BEZERRA, 2015). Essa "voz pessoal", de acordo com Ivanič (1998), se dá pela intertextualidade. Na ótica de Ivanič (1998), a noção de intertextualidade contribui para uma teoria da identidade do escritor por destacar que essa identidade, por um lado, não é nova nem individual, e, sim, constituída pelos discursos que adota; por outro lado, é parcialmente determinada pelo modo particular como o escritor combina ou lança mão dos discursos de outros.

Na mesma direção de Wellington, o discente Cleiton, ao discutir sobre as dificuldades enfrentadas para escrever academicamente no ProfEPT, nos aponta que

\footnotetext{
o que me deixava/ um pouco/ASSIM/talvez/inquieto/ era muito/ essa/ questão de/ pelo menos/ quando/se vai montar/um projeto/é uma necessidade/ constante/ pelo menos isso/ em metodologia/né?/ uma necessidade/ constante de citar/de embasar/ o que você está querendo/a sua ideia/em algum autor/(CLEITON).
}

A ênfase dada por Cleiton ao dizer "o que me deixava um pouco ASSIM" nos mostra uma certa inquietação em relação ao ato de citar. Para ele, é difícil fundamentar seu discurso em algum autor 


\section{REVISTA DA ABRALIN}

que tem autoridade no meio acadêmico. Talvez, isso ocorra pelo fato de ele considerar que a academia o julga uma pessoa sem autoridade, logo sem conhecimento. Ivanič (1998), ao tratar sobre essa visão de si mesmo como pessoa sem autoridade, nos lembra que a maioria dos escritores com quem ela já trabalhou tinha um sentimento de inferioridade diante do seu fazer acadêmico. Lea (1999), por sua vez, nos alerta que a simples reprodução do conhecimento acadêmico pode parecer invalidante e restritiva e pode entrar em conflito com outras "formas de conhecimento" mais familiares que os alunos já possuem.

Em outro trecho da entrevista de Cleiton, novamente, evidenciamos sua inquietação com relação ao ato de citar. Ele nos diz que "teve uma aula/ em que a pessoa/ INSISTIA muito nisso/ de ficar o tempo inteiro/ NISSO/ se você falar/o Brasil/ é um pais/de extensa dimensão territorial/é um país grande/você tem que falar quem falou isso/e / ai / que já não concordo/ sabe? /"

Destacamos do fragmento acima, as ênfases dadas por Cleiton por meio das palavras "INSISTIA" e "NISSO". A insistência, para ele, foi dada numa determinada aula por um professor do ProfEPT quando esse estava ensinando sobre citação. Já "NISSO" refere-se ao ato de citar que, para o aluno, em certa medida, é desnecessário. A situação apresentada por Cleiton nos leva a pensar que o discente se opõe, nos termos de Chase (1988, p.15), ao ato de citar. Segundo o referido autor, a oposição se refere ao comportamento de alunos que negam "certos padrões e convenções de uma comunidade em particular e não conseguem se envolver em comportamentos que os capacitariam a aprender essas convenções".

Dentro do jogo da escrita na universidade, que é a identidade de uma pessoa com autoridade, verificamos, ainda, na fala de Isaque, abaixo, esta ocorrência:

\footnotetext{
Na qualificação/ houve um debate/ [...]

[...] existia uma expressão/ que eu usava/ [...]

[...] era quando/ eu me referia/ a uma visão idealista de escola/ certo/ e/ essa visão/ idealista/ eu dizia/ categoricamente/ que/ nós/ não podemos/idealizar a escola/certo/ só que eu dizia/ que/ uma escola idealizada/ ela não existia/ era algo/ mais de conteúdo/ era isso/ só que/ era uma opinião/ tão subjetiva/ que não tinha/ apesar de fazer / ter coerência textual/ está empregada/dentro de uma redação/fazer algum sentido/ ela estava deslocada/de um debate científico / a medida/ porque / eu não apresentava/ por exemplo/ ideias de outros autores/sobre esse tema/ ou pesquisas/ que fundamentassem/ a minha opinião/(ISAQUE).
}

Nesse fragmento, notamos que a banca de qualificação sugeriu que o discente fundamentasse o seu discurso, por meio de citações, para que ele pudesse ser aceitável à comunidade acadêmica. Ao tratar sobre essa necessidade de evocação de discursos já existentes e conhecidos, De Paula (2017, p.96), nos lembra que, sem a citação, "o autor pode não ser considerado um pesquisador sério, por ignorar autores 'consagrados' em certo campo de pesquisa". Fica evidente, então, que nesse contexto, banca de qualificação, há "relações de poder que legitimam o que 'pode ou não' no campo científico, o que 'deve ou não' ser citado para validar o discurso acadêmico". 


\title{
REVISTA DA ABRALIN
}

Além dos aspectos intertextuais, constatamos na fala dos participantes da pesquisa elementos referentes a normatização dos textos acadêmicos. No trecho abaixo, Isaque sintetiza, por meio de dois elementos, os desafios enfrentados por ele ao escrever no ProfEPT:

\begin{abstract}
tem/duas coisas/que/ eu acho/ que/saltaram/ aos olhos/ com respeito a essas dificuldades/ primeiro/ a formalidade acadêmica/ certo? / as regras de escrita acadêmica/ [...] uma segunda/que eu acho/ que reflete muito mais/o Isaque professor/o pesquisador/que é/as afirmativas / ou/a defesa de ponto de vista/que/ eu acho / que/ em muitos cenários/ é muito válido/ necessário/mas que/ numa produção acadêmica/ aquele debate/que a gente faz/ precisa estar fundamentado/ em produções anteriores/ certo/ [...] (ISAQUE).
\end{abstract}

Nesse excerto, verificamos que, além dos aspectos referentes às questões de intertextualidade, observamos na fala do participante questões ligadas à normatização do texto acadêmico. É interessante destacar que, para o discente, não se trata somente da normatização, algo estrutural, como regras da $\mathrm{ABNT}$ e formatação, etc. Isaque tem clareza dos jogos que estão por trás das citações ao dizer: "reflete muito mais/ o Isaque/ professor/ o pesquisador/". É, para ele, então, a defesa do seu ponto de vista que está relacionado com as questões identitárias, as dialógicas e as sociais.

Da mesma forma que Isaque, identificamos na fala de Wellington essa questão da normatização. Para ele, a escrita acadêmica o incomoda "posto que é/ uma escrita/ bem quadrada/ uma escrita/ bem fechadinha/ e toda cheia de/ seus parâmetros/e/ eu não sei/ se deve ser ASSIM/".

Ao afirmar que "eu não sei/ se deve ser assim/", Wellington nos possibilita refletir sobre a ideia da escrita "não apenas em termos tecnicistas e estruturais, mas como uma dimensão estética, marcada por relações de poder que constituem a identidade dentro das produções textuais" (DE PAULA, 2017, p. 86). De Paula (2017), ao refletir sobre esses aspectos tecnicistas e estruturais, nos lembra que

\begin{abstract}
De modo geral, então, pode-se dizer que os manuais, e também muitas das práticas acadêmicas nas quais os estudantes são inseridos, privilegiam apenas a norma sem a problematização necessária da citação ou mesmo da identidade de autor, e sem "espaço de manobra", ou seja, é o ensino e a prática de normas engessadas que negam o caráter dialógico da citação enquanto escolha identitária e interação necessária, o que leva a uma negação das vozes que permeiam o discurso, uma vez que é suficiente citar para se adequar às normas técnicas e acadêmicas. Logo, o risco dessa abordagem, comprovado nos dados apresentados pelos autores, é citar por citar, citar apenas para inserir uma voz consagrada no discurso com o objetivo principal de que este seja reconhecido na comunidade acadêmica, atentando apenas para aspectos estruturais e normativos. (DE PAULA, 2017, p.88).
\end{abstract}

Esse perigo apontado por De Paula (2017), qual seja, citar por citar, nega a dimensão discursiva da citação na universidade. E se aproxima do modelo autônomo de letramento, visto que o letramento é considerado como uma habilidade técnica e neutra (STREET,1984; 2013). Na mesma direção, Terzi (2006, p.7-8) nos rememora que o autor, numa perspectiva autônoma do letramento, "é somente "o redator do texto, quase que um anônimo". Ao contrário, ou seja, na perspectiva do modelo ideológico de letramento, o autor não é apenas o redator do texto; ele é, segundo Terzi (2007, p.78), "um membro da comunidade com formação individual e social, com valores, crenças, opiniões 


\section{REVISTA DA ABRALIN}

próprias, profissão, identidade etc. e com o poder de ter seus textos publicados, privilégio atribuído a poucos pela classe dominante".

\section{Considerações finais}

Esse texto objetivou compreender os sentidos e os desafios enfrentados pelos discentes do ProfEPT, que atuam como professores, para escrever academicamente num mestrado profissional. O ProfEPT é um programa recém criado e tem como objetivo proporcionar a formação em educação profissional e tecnológica aos profissionais da Rede Federal de Educação Profissional e Tecnológica.

A partir do levantamento dos gêneros textuais e das funções desses gêneros no contexto do curso, foi possível perceber que as práticas de escrita ocorridas no ProfEPT não se limitaram tão somente aos gêneros produzidos no contexto acadêmico (dissertação, projeto de pesquisa, produto educacional, artigo, resenha, resumo e fichamento), mas estão relacionadas também às práticas específicas da academia com usos e significados próprios, como a formulação de questões e a redação.

Com relação aos desafios enfrentados pelos discentes para escrever academicamente num mestrado profissional, observamos que os alunos (embora sejam graduados em áreas distintas do conhecimento: ciências exatas, ciências humanas e linguagens) indicaram tensões ao se referirem à escrita acadêmica. Tal fato é significativo, visto que havia uma expectativa de que o participante formado em Letras não apontasse desafios no que concerne à escrita acadêmica.

Outro aspecto relevante, quando discutimos sobre os desafios para escrever academicamente no ProfEPT, trata-se das questões ligadas à identidade; logo, intertextuais. Nesse contexto de formação, a citação é uma das modalidades de apropriação do discurso do outro. Verificamos que os estudantes incorporaram em seus discursos autores consagrados do meio acadêmico. Vimos que a identidade está ligada à interação cotidiana com os discursos acadêmicos institucionalizados e apreendidos em sala de aula, em textos, em discussões, na qualificação e outros. Ao fazer suas escolhas discursivas, o aluno está se alinhando a uma forma de escrita e construindo sua identidade afinada com aqueles que fazem escolhas similares. Por outro lado, notamos também oposição (CHASE, 1988) às formas de citação. Há, por parte dos discentes, uma necessidade de assumir-se autor, ocupar essa posição, e se representar nesse lugar: reconhecer-se e representar-se capaz de dizer o que quer dizer.

Este artigo não intenta apontar caminhos que possam melhorar o ensino da escrita no contexto acadêmico. Contudo, entendemos que ele fornece indicadores aos professores e aos coordenadores de cursos de mestrados profissionais sobre qual é a condição letrada dos alunos que voltam para a universidade para realizar uma formação continuada, bem como sobre quais são suas expectativas em relação ao ensino da escrita nesse domínio, para que possam desenvolver estratégias mais eficazes que promovam o desenvolvimento das formas de ser, pensar, agir, escrever e ler próprias dessa esfera. Com relação à trabalhos futuros, apontamos a necessidade de pesquisas que se voltam para organização do currículo de cursos de pós-graduação, visto que essa formação não deve ignorar as dimensões escondidas na citação da voz do outro. 


\title{
REVISTA DA ABRALIN
}

\author{
REFERÊNCIAS
}

BADENHORST, C.; GUERIN, C. Post/ Graduate research literacies and writing pedagogies. In: BADENHORST, C.; GUERIN, C. (Orgs.). Research literacies and writing pedagogies for masters and doctoral writers. Leiden: Brill, 2016.

BEZERRA, B. Gêneros acadêmicos em cursos de especialização: conjunto ou colônia de gêneros? RBLA, Belo Horizonte, v. 12, n. 3, p. 443-461, 2012.

BEZERRA, B. Letramentos acadêmicos e construção da identidade: a produção do artigo científico por alunos de graduação. Linguagem em (Dis)curso - LemD, Tubarão, SC, v. 15, n. 1, p. 61-76, jan./abr. 2015. Disponível em: https://www.scielo.br/pdf/ld/v15n1/1518-7632-ld-15-01-00061.pdf. Acesso em: 14 dez. 2020.

BRASIL/ ProfEPT. Anexo ao Regulamento do ProfEPT. 2018. Disponível em:

https://profept.ifes.edu.br/images/stories/ProfEPT/Turma_2018/Regulamento/Anexo-ao-Regulamento2019.pdf. Acesso em: 21 abr. 2021.

CASTANHEIRA, Maria Lucia; GREEN, Judith L.; Dixon, Carol N. Práticas de letramento em sala de aula: uma análise de ações letradas como construção social. Revista Portuguesa de Educação, vol. 20, núm. 2, 2007, pp. 7-38. Universidade do Minho, Braga, Portugal. Disponível em: https://www.redalyc.org/pdf/374/37420202.pdf. Acesso em: 21 abr. 2021.

CHASE, G. Accommodation, Resistance and the Politics of Student Writing. College Composition and Communication, vol. 39, $\mathrm{n}^{\circ} .1,1988$. Disponível em: https://www.jstor.org/stable/357812?seq=1. Acesso em: 29 dez. 2020.

DE PAULA, D. A questão da identidade na escrita acadêmica. SCRIPTA, Belo Horizonte, v. 21, n. 43, p. 86-104, $2^{\circ}$ sem. 2017. Disponível em: file:///C:/Users/rasor/Downloads/14830-Texto\%20do\%20artigo-59880-1-1020180115\%20(1).pdf. Acesso em: 24 dez. 2020.

FIAD, R. A escrita na universidade. Revista da ABRALIN, v. Eletrônico, n. Especial, p. 357-369. 2. parte, 2011.

FIAD, R. S. Reescrita, dialogismo e etnografia. In: Linguagem em (Dis)curso, v. 13, n. 3, 2013, p. 463-480.

GREEN, J.; BLOOME, D. Ethnography and ethnographers of and in education: a situated perspective. In FLOOD, J; HEATH, Shirley; Lapp, D. (Ed.). Handbook of research on teaching literacy through the communicative and visual arts. New York: Simon \& Schuster Macmillan, p. 181-202, 1997.

HEATH, S. B. Protean shapes in literacy events: ever-shifting oral and literate traditions. In: TANNEN, D. (Org.). Spoken and written language: exploring orality and literacy. Norwood, N.J.: Ablex, 1982. p. 91-117.

IVANIČ, R. Studies in written language and literacy: Writing and identity - the discoursal construction of identity in academic writing. 1998. Disponível em: https://ebookcentral.proquest.com. Acesso em: 21 abr. 2020.

KLEIMAN, A.; MATÊNCIO, M. Letramento e formação do professor: representações e construção do saber. Campinas: Mercado das Letras, 2005.

LEA, M. R.; STREET, B. V. Student writing in higher education: an academic literacies approach. In: Studies in Higher Education, Abingdon, Oxon, UK, v. 23, n. 2, p. 157-172, 1998.

LEA, M. R.; STREET, B. V. O modelo de "letramentos acadêmicos": teoria e aplicações. Tradução de Fabiana Komesu e Adriana Fischer. In: Filologia e Linguística Portuguesa, v. 16, n. 2, 2014, p. 477-493. 


\section{REVISTA DA ABRALIN}

LEA, M. R. Academic Literacies and Learning in Higher Education Constructing knowledge through texts and experience. In: JONES, C., TURNER, J., \& STREET, B. (Eds.). Students writing in the university: Cultural and epistemological issues. 1999. Disponível em: https://ebookcentral.proquest.com. Acesso em: 21 abr. 2020.

LILLIS, T.; SCOTT, M. Defining academic literacies research: issues of epistemology, ideology and strategy. Journal of Applied Linguistics. vol 4.1, 2007, p.5-32. Disponível em: http://www.equinoxpub.com/JAL/article/viewArticle/4563. Acesso em: 01 jun. 2012.

PARIS, P. Letramentos acadêmicos de doutorandos: entre mediações e publicações. Tese (Doutorado em Linguística Aplicada) - Instituto de Estudos da Linguagem da Universidade Estadual de Campinas, Universidade de Campinas. Campinas. 2021.

NEVES, V. Tensões Contemporâneas no Processo de Passagem da Educação Infantil para o Ensino Fundamental: um Estudo de Caso. 2010, 271f. Tese (Mestrado em Educação) - Universidade Federal de Minas Gerais, BELO HORIZONTE, 2010

SARMENTO, M. O estudo de caso etnográfico em educação. In: ZAGO, N; CARVALHO, M; VILELA, R. Itinerários de Pesquisa: perspectivas qualitativas em sociologia da educação. Rio de Janeiro: Lamparina, 2011.

SCHNEUWLY, Bernard \& DOLZ, Joaquim. Os gêneros escolares: das práticas de linguagem aos objetos de ensino. In: Revista Brasileira de Educação, nº 11, p.5-16, 1999.

STREET, B. V. Literacy in theory and practice. Cambridge: Cambridge University Press, 1984.

STREET, B. V. Introduction: the new literacy Studies. In: STREET, B. Cross-Cultural Approaches to Literacy. Cambridge: Cambridge University Press, 1993.

STREET, B. V. Literacy and development: ethnographic perspectives on schooling and adult education. In: STREET, B. V. (Ed.). Literacy and Development: Ethnographic perspectives. London and New York: Routledge, 2001.

STREET, B. V. What's "New" in New Literacy Studies? Critical approaches to literacy in theory and practice. Current Issues in Comparative Education. Teachers College, Columbia, University, 2003.

STREET, B. V. Políticas e práticas de letramento na Inglaterra: uma perspectiva de letramentos sociais como base para uma comparação com o Brasil. Cad. CEDES, vol.33 n. 89 Campinas Jan./Apr. 2013. Disponível em: http://dx.doi.org/10.1590/S0101- 32622013000100004. Acesso em: 20 jun. 2014.

TERZI, S. B. A construção do currículo nos cursos de letramento de jovens e adultos não escolarizados. 2006. Disponível em: http://www.cereja.org.br/arquivos_upload/sylviaterzi.pdf. Acesso em: 01 abr. 2015.

WOLCOTT, H. F. Description, analysis, and interpretation in qualitative inquiry. In: WOLCOTT, H. F. (Org.). Transforming qualitative data: description, analysis, and interpretation. Thousand Oaks, CA: Sage, 1994. p. 9-54. 